\title{
News in Cancer-Related Pain Management
}

Cornelia NITIPIR 1,3, Andreea PAROSANU', Lucian ALECU², Ana Maria POPA ${ }^{1,3}$, Cristian IACIU1,3, Mihaela OLARU', Adrian TULIN², Iulian SLAVU², Valentin CALU', Cristina ORLOV-SLAVU'

\begin{abstract}
Introduction: Cancer related- pain causes a negative psychosocial and physical impact on patients' lives. The purpose of this review was to investigate the current strategies for cancer pain treatment. Material and Methods: We conducted a PubMed search of the literature published from 2018 to 2020, and details were extracted from the articles with adequate study quality. Discussion: Of 63 titles, 19 studies were selected and used in review. Conclusions: This review article focuses on the novel treatments available for cancer pain management.
\end{abstract}

Keywords: cancer-related pain, opioids, alternative treatments.

\section{Rezumat}

Durerea cauzată de cancer induce efecte negative atât fizice cât și psihologice pacienților. Scopul acestei recenzii a literaturii a fost să identifice tehnici noi de a ușura durerea pacienților oncologici. Material și metodă: S-a efectuat o căutare în baza de date PubMed care a avut în vedere identificarea articolelor în acest domeniu, publicate între 2018 și 2020. Au fost identificate 63 de titluri, dintre care au fost selectate manual 19. Discuții: Particularitățile rezultatelor fiecărui studiu au fost explicate și s-a căutat o aplicabilitate a acestora. Concluzii: Managementul durerii în cancer, deși standardizat de o perioadă lungă de timp, mai lasă loc de îmbunătătire.

Cuvinte cheie: durerea cauzată de cancer, opioide, tratamente alternatice.

\section{INTRODUCTION}

In patients with advanced or metastatic cancer, the prevalence of pain is estimated to be more than $70 \%$, although pain is also frequent in some early stages of pancreatic cancer $(44 \%)$ or cancer in the head and neck $(40 \%)^{1,2}$.

Therefore, the management of long-term pain is a crucial part in a comprehensive approach of palliative care. The present paper is a general review on this topic that aims to present the most recent results in this field and how practitioners can integrate them in their daily care routine.

\section{MATERIALS AND METHODS}

The search for the present review was conducted in the PubMed database, in English, using as key words cancer pain [MeSH Terms] and sought to identify all clinical trials that included cancer pain in the abstract, published from 2018 to 2020 . A total of 63 publications were found, and 31 satisfied our inclusion criteria
${ }^{1}$ Clinic of Oncology, Elias Emergency University Hospital, Bucharest, Romania

${ }^{2}$ Clinic of General Surgery, „Agrippa Ionescu" Emergency Hospital, Bucharest, Romania

3 "Carol Davila" University of Medicine and Pharmacy, Bucharest, Romania

${ }^{4}$ Clinic of General Surgery, Elias Emergency University Hospital,

Bucharest, Romania
Corresponding author. Andreea PAROSANU, $17^{\text {th }}$ Marasti Boulevard, 011461, Bucharest, Romania.

E-mail: aparosanu@yahoo.com 
of reporting randomized, phase III, or II clinical trials, published since 2018. Studies including children and studies without statistical relevance were ruled out. Finally, we chose the 19 most relevant studies.

\section{DISCUSSION}

After the analysis of the 19 most relevant trials, most important information was organised and presented in the following paragraphes.

\section{Pain assessment}

The grading of pain uses multidimensional assessments and initial and ongoing evaluation has an important role in cancer care.

The most commonly utilized systematic scales are the visual analog scale (VAS), the verbal rating scale (VRS), and the numerical rating scale (NRS). The severity of distress and the therapy effects must be monitored consistently and orderly, applying a simple question: 'How can you describe the strongest pain in the last 24 hours?' Thus, 3 levels of pain intensity are described: mild pain (1-3 score), moderate pain (4-7 score), and severe pain (8-10 score).

When facing a patient with severe cognitive deficits, it is necessary to observe behaviors related to pain such as facial and body expressions and movements, changes in routine activity, or interpersonal interactions. These are alternative approaches for evaluating the existence of pain, without quantifying its severity ${ }^{3}$.

When prescribing pain therapy, it is important that the drug can be directly administered by patients or their families. Oral administration should always be preferred. The dose and type of analgesic drugs need

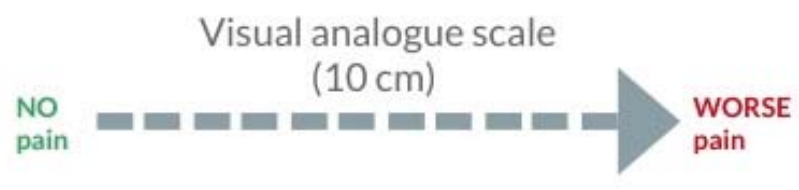

Figure 1. Visual analogue scale.

\section{Numerical rating scale}

\section{0 worsE pain}

Figure 2. Numerical rating scale.
Verbal rating scale

$\begin{array}{ll}1 & \text { no pain } \\ 2 & \text { very mild } \\ 3 & \text { mild } \\ 4 & \text { moderate } \\ 5 & \text { severe } \\ 6 & \text { very severe }\end{array}$

Figure 3. Verbal rating scale.

to be efficiently adapted to achieve a stability among optimal distress remission and lowest side reactions.

\section{Opioids and other pharmacological treatments}

WHO proposes a scheme regarding cancer pain therapy, based on a series of sequential steps, beginning with non-opioids, weak opioids up to strong opioids ${ }^{4}$.

Strong opioids represent the mainstay of painkillers. In the opinion of ESMO-EAPC report (European Society for Medical Oncology-European Association of Palliative Care), there is a variety of strong opioids (morphine, fentanyl methadone, oxycodone, and other), but morphine is the most extensively disposable and recommended 5 .

Effective alternatives to oral morphine are oxycodone or hydromorphone and oral methadone.

To compare the effects on quality of life regarding treatment with oral administrated morphine and transdermal patches of fentanyl, a randomized clinical trial evaluated oncological patients with strong pain (NRS score 6-10) and who did not answer to weaker or non-opioids. 62 subjects were enrolled to receive up to 28 days, treatment with morphine, oxycodone, fentanyl, or buprenorphine. All 4 opioids significantly improved patients' quality of life with similar adverse effects; according to BPI-SF (Brief Pain Inventory Short Form), morphine, however, induced fewer unpleasant effects on daily routine (to walk and normal work) and greater improvement in physical functioning according to HADS (HADS Hospital Anxiety and Depression Scale) ${ }^{6}$.

Opioids do not invariably relieve cancer pain. Up to $20 \%$ or $25 \%$ of patients treated with opioids do not obtain more than $30 \%$ pain reduction ${ }^{7}$.

Uncontrolled cancer-related pain can require dose adjustments that also increase drug toxicity. In some of these cases, an opioid switch can be chosen. 


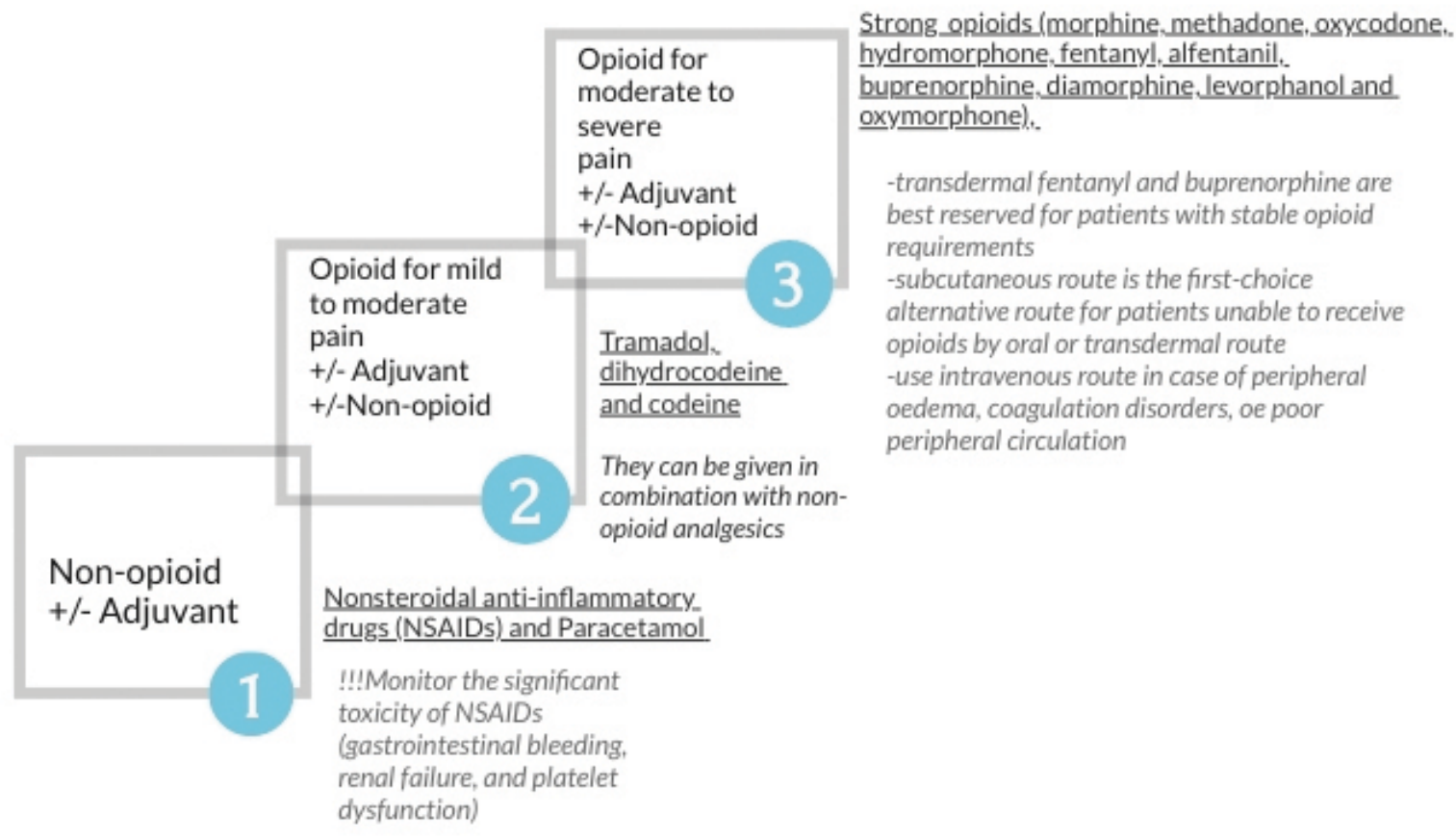

Figure 4. Cancer pain ladder.

A multicenter, open-label, longitudinal, phase IV study, randomized 498 subjects with metastatic cancer, and tenacious moderate to severe cancer pain $(\geq 4$ assessed on Numerical Rating Scale) to orally administered morphine, or transdermal fentanyl. Over 4 weeks of follow-up, the researchers investigated the necessity for an opioid switch, recording all changes in the pain therapy (motive for the switch, percentages of switches). The pain was considered uncontrolled when the drug could not reduce the pain by at least $30 \%$.

Data reported that $15.9 \%$ of patients switched the opioid, particularly for out of control pain (52.3\%), adverse opioid reactions (22.1\%), and dysphagia (20.8\%). Pain reduction was improved by $51.45 \%$ after switching with better management of opioid adverse reactions in $43.5 \%$ of cases. In conclusion, opioid switching improved distress remission and lowered side effects in almost half of patients ${ }^{8}$.

Data reveal alternatives for complementing analgesia in progressive cancer with unsuppressed pain. An extract of Cannabis sativa, called Nabiximols, showed its' utility in randomized phase III study, in patients with metastatic tumors and moderate pain (NRS scores 4-8), with step 3 opioid treatment. 397 patients randomly received placebo, or nabiximols, an oral mucosal spray, administered as a unique dose on initial day of therapy and then gently titrated by single supplementary spray daily until patients achieved reasonable pain remission, or developed unacceptable side effects. Efficacy was assessed using the NRS score. Results proved the efficacy of Nabiximols in patients with persistent unsuppressed pain, with a median $10.7 \%$ improvement in pain control in the nabiximols arm, versus $4.5 \%$ in the placebo arm (95\% CI: $0.00 \%-8.16 \% ; p=0.0854)^{9}$.

When conventional treatments become limited, supportive methods can be associated to improve pain management. In this circumstance, ear acupuncture or auriculotherapy demonstrated positive outcomes in a randomized clinical trial on 31 patients with cancerrelated pain (pain $\geq 4$, assessed by the Numerical Pain Scale (NPS)). After 8 auricular acupuncture sessions, patients in the experimental group had pain classified as mild by NPS $(2.09 \pm 1.44)$, while the placebo arm proceed the average pain the same as at baseline point $(6.33 \pm 2.14)$, with meaningful lowering in quotidian amount of painkillers $(\mathrm{p}=0.010)$ and the multitude of painkillers utilized $(p=0.019)$ for the studied group. Therefore, auricular acupuncture is a complementary therapy that provides lowest side effects and can reduce the use of painkillers ${ }^{10}$. 


\section{Invasive management of refractory pain}

Regardless of extreme medical therapy, approximately $30 \%$ of oncological patients still have uncontrollable pain $^{11}$.

There is a long history of neurosurgical interventions for pain control, including lesion inducing techniques targeting the spinal marrow or even the brain ${ }^{12}$.

A prospective randomized study enrolled 16 oncological patients with refractive nociceptive pain (assessed by the Edmonton Symptom Assessment Scale), who underwent 3 supportive care assessments. Subjects were selected to proceed with percutaneous computed tomography guided interventional cordotomy or to continue multidisciplinary supportive care. The aim of cordotomy is the disrupt the pain pathway from the thalamus to the spinal cord.

The initial result was 33\% reduction in pain intensity after 1 week, providing evidence for the usage of cordotomy in intractable cancer-related pain ${ }^{13}$.

Endoscopic ultrasound-guided celiac plexus neurolysis (EUS-CPN) and, endoscopic ultrasound-guided radiofrequency ablation (EUS-RFA) are indicated to alleviate pain in pancreatic cancer. A randomized controlled trial of 26 patients with advanced or metastatic pancreatic cancer and abdominal pain experienced one of two procedures. Grading was determined by the EORTC PAN26 questionnaire (European Organization for Research and Treatment of Cancer-Quality of Life Questionnaire pancreatic cancer module), before treatment and at 2 or 4 weeks after interventions. Both procedures were effective in reducing pain and enhancing the general well-being: at 4 weeks follow up, pain scores were remarkably lessen in the EUS-RFA arm compared with EUS-CPN (49.0 versus 57.0, p <0.001) ${ }^{14}$.

In a recent randomized prospective clinical trial, transcranial direct current stimulation has been proven to reduce visceral pain due to hepatocarcinoma. The patientss pain was evaluated by the visual analog scale and verbal descriptor scale (VDS and VAS). Depression grading was done for the enrolled patients by Hamilton rating scale (HAM-D). In all 40 patients enrolled, transcranial direct current stimulation induced positive effects on pain and depression, compared to placebo; VDS ( $p=0.001)$, VAS ( $p=0.001)$, HAM$\mathrm{D}(\mathrm{p}=0.012)^{15}$.

Intrathecal drug administration or epidural management of opioids can be helpful in patients with insufficient pain relief regardless of the great amount systemic analgesia. A prospective, long-term, multicenter study, analyzed 1403 patients with cancer pain and intrathecal drug transporting systems, using a EuroQol health status questionnaire. It aimed to establish the safety and effectiveness of intrathecal drug delivery systems as a therapeutic option for the management of cancer pain and pain scores improved significantly at 6 months $(p=0.0007)$ and 12 months $(p=0.0026)$ compared to baseline ${ }^{16}$.

\section{Breakthrough cancer pain}

Breakthrough cancer pain (BTcP), is described as a transient exacerbation of pain that arises on a context of comparatively well-controlled baseline pain, which is greater than moderate intensity. The actual accordance describes BTcP as an event of moderate to severe pain, with a fast onset and brief duration ${ }^{17}$.

Breakthrough cancer pain (BCP) has yet to be optimally treated; opioids being the usual treatment, but their pharmacokinetic and pharmacodynamic profiles (the beginning of analgesia in 20-30 minutes, with the climax in 60-90 minutes and 3-6 hours duration of effect) do not correspond with the typical onset of a BTcP. Various transmucosal fentanyl formulations with have demonstrated the efficacy with meaningful analgesia within 5 to 15 minutes, but these formulations must be titrated to an functional and acceptable dosage for each individual subject ${ }^{18}$.

Oral transmucosal fentanyl has the serious adverse effects associated with all opioids, and the dose-dependent respiratory effects have been compared with intravenous morphine ${ }^{19}$.

Cancer patients with breakthrough cancer pain usually present in the emergency department and need rapid pain relief. Therefore, a single-center study randomized 82 patients with severe cancer pain ( $\geq 7$ on a 1-10 pain scale), to receive intranasal fentanyl or intravenous opioids. The analyses presented non-inferiority between the 2 administrations, but compared to intravenous opioids (the median pain score at 1 hour of administration was 8.5 for the fentanyl arm and 9 for the intravenous arm), intranasal fentanyl had the advantage of the noninvasive way of distribution, fast onset of action ( 15 minutes vs 23 minutes, $p<0.001$ ) and optimal bioavailability with the escape of first pass metabolism that occur in the liver ${ }^{20}$.

Inhaled nitrous oxide/oxygen determines analgesia without syncope and the gas is easily absorbed from the bloodstream; it delivers express relief from pain and restlessness, but this remission is rapidly inverted after stopping treatment. Thereby a double-blind, randomized study assigned 40 oncological patients with 
breakthrough pain who received randomly the ordinary pain treatment with morphine plus nitrous oxide versus the standard pain treatment plus oxygen. At only 5 min after starting of treatment, the pain outcome significantly decreased in the nitrous oxide arm $(2.8 \pm 1.3$ versus $5.5 \pm 1, \mathrm{p}<0.012$ ). After $15 \mathrm{~min}$, the average pain score remained lower in the first group $2.0 \pm 1.1$ Vs $5.6 \pm 1.3$ ( $p<0.01)$. In conclusion, nitrous oxide/ oxygen compound may be used to decrease moderateto-severe BTP, because of its palliative attributes and reduced prevalence of adverse reactions ${ }^{21}$.

\section{Neuropathic cancer pain}

Cancer-related neuropathic pain could be a immediate effect of a cancer-induced lesion to the somatosensory system, or the acute or chronic effects of radiotherapy and chemotherapy.

Neuropathic pain demands multiple drug therapy, with analgesics, corticosteroids, antiepileptics, and depression medications ${ }^{22}$.

Though the management of neuropathic pain that is do not respond to opioids and gabapentinoids is an significant provocation, duloxetine proved effective, as presented in the JORTCPAL 08 trial. This prospective, randomized, double-blind trail enrolled 70 patients with cancer neuropathic pain (assessed by The Brief Pain Inventory), unresponsive or allergic to opioids and compared the efficiency of duloxetine associated with opioid therapy with placebo for 10 days. Patients with chemotherapy-induced peripheral neuropathies were not included this study.

Clinically considerable pain relief (44.1\% duloxetine group vs $32.4 \%$ in the placebo group) was obtained for duloxetine with marginal statistically pain reduction according to BPI- Item 5 scores on Day 10 of treatment (4.03 in duloxetine group vs. 4.88 in the placebo group, $\mathrm{p}=0.053)$. Thus, adding duloxetine to opioidpregabalin treatment could be efficient for cancer neuropathic pain ${ }^{23}$.

\section{Alternative treatments}

Is cognitive-behavioral strategies (CBS) an effective intervention targeting cancer-related pain? A randomized controlled study, including 164 patients with advanced neoplasia and cancer-related pain, tried to answer this question. To manage distress, tiredness, and insomnia, over a 9-week follow-up, patients were practicing relaxation, or listened to cancer education registrations (attention-control). Using a $0-4$ pain and distress scale, participants receiving the cognitive-be- havioral strategies had fewer symptoms after 6 weeks of intervention $(p<0.05)$. Even if this brief cognitivebehavioral intervention had limited effects in this trial, these findings provide insight into ways to decrease the pain $^{24}$.

Pain occurring after breast surgery in the shoulders and arms, is one of the major musculoskeletal issues, expressing psychological and emotional distress. According to a prospective, randomized, controlled, singleblind study on 42 patients with breast cancer pain, yoga was a mind-body exercise with properties that would qualify it as a complementary or alternative therapy for patients with cancer. After a 10-week Hatha yoga program, 22 patients from the exercise group showed a significant improvement in both shoulder and arm pain severity from baseline ( $\mathrm{p}=0.01)$, with benefits preserved at 2.5 months post-treatment $(p=0.01)$ compared to the control group ${ }^{25}$.

Traditional Chinese medicine for cancer pain involves the application of Chinese herbal warm compress, designed for cancer pain relief by stimulating the blood flux through the back meridians, and rise the peripheral delivery of endogenous pain-relieving agents. This combination of herbs can decrease blood pressure, improve microcirculation, and have analgesic and anti-inflammatory effects.

According to a Chinese clinical trial, the application of medicine warm compress in combination with WHO 3-step analgesic ladder therapy was efficient in alleviating cancer pain and improved the general wellbeing of cancer patients. Overall, 62 patients suffering from cancer-related pain were randomized appropriate treatment according to the World Health Organization (WHO) 3-step ladder, plus external treatment with a warm compress on back meridians, or plus placebo. Pain relief was evaluated practicing the visual ana$\log$ scale. The general response rate was meaningfully better in the interventional group compared to placebo (70.97\% vs $29.03 \%$, p $<0.001)$. Moreover, the adjuvant analgesic doses were significantly lower $(12.90 \%$ vs $22.58 \%, \mathrm{p}=0.023)^{26}$.

\section{Future perspectives}

Is the use of mobile technology a key factor in advancing the science of symptom management?

Even if not scientifically validated, there are 165,000 medical and health applications ${ }^{27}$.

Considering that, a mobile phone application designed by physicians in partnership with engineers, known as Pain Guard, was tested for pain control in oncologi- 
cal patients. Pain Guard was designed to daily assessed patients for cancer pain and breakthrough cancer pain $(\mathrm{BTcP})$, using a questionnaire that consisted of $12 \mathrm{qu}-$ estions, including assessment of pain intensity by a numerical 1 to 10 rating scale; the location of the pain (the app had a body map to allow a precise location of recently experienced cancer pain), the character of the pain, and any adverse drug effects.

A double-arm randomized trial enrolled 58 patients with cancer-related pain, to acquire care through the Pain Guard application or only traditional pharmaceutical care. After 4 weeks follow up, the Pain Guard app successfully increased the management of pain control $(\mathrm{p}<0.001)$, with a considerably higher rate of medication adherence $(p<0.001)$, and improvements in global quality of life $(\mathrm{p}<0.001)$ compared to placebo ${ }^{28}$.

\section{References}

1. Portenoy RK. Treatment of cancer pain. Lancet. 2011 Jun 25;377(9784):2236-47. DOI: 10.1016/S0140-6736(11)60236-5. PMID: 21704873.

2. Burton AW, Fanciullo GJ, Beasley RD et al. Chronic pain in cancer survivor: a new frontier. Pain Med 2007; 8: 189-198.

3. Clemons M. J., Ong M., et al, A randomized trial comparing four-weekly versus 12-weekly administration of bone-targeted agents (denosumab, zoledronate, or pamidronate) in patients with bone metastases from either breast or castration-resistant prostate cancer. Journal of Clinical Oncology 37, no. 15 suppl (May 20, 2019) 11501-11501.

4. https://www.who.int/cancer/palliative/painladder/en/, accessed on 27.10 .2020

5. Cherny NI, Baselga J, de Conno F, Radbruch L. Formulary availability and regulatory barriers to accessibility of opioids for cancer pain in Europe: a report from the ESMO/EAPC Opioid Policy Initiative. Ann Oncol 2010; 21: 615-626.

6. Leppert W, Nosek K. Comparison of the Quality of Life of Cancer Patients with Pain Treated with Oral Controlled-Release Morphine and Oxycodone and Transdermal Buprenorphine and Fentanyl. Curr Pharm Des. 2019;25(30):3216-3224. DOI: 10.2174/13816128256661907 17091230. PMID: 31333114.

7. Corli O, Floriani I.et al. CERP STUDY OF PAIN GROUP (List of collaborators), CERP STUDY OF PAIN GROUP (2016) Are strong opioids equally effective and safe in the treatment of chronic cancer pain? A multicenter randomized phase IV 'real-life' trial on the variability of response to opioids. Ann Oncol Off J Eur Soc Med Oncol 27:1107-1115.

8. Corli $\mathrm{O}$, Roberto $\mathrm{A}$, et al. Opioid switching and variability in response in pain cancer patients. Support Care Cancer. 2019 Jun;27(6):2321-2327. doi: 10.1007/s00520-018-4485-6. Epub 2018 Oct 24. PMID: 30357556.

9. Lichtman AH, Lux EA, et al. Results of a Double-Blind, Randomized, Placebo-Controlled Study of Nabiximols Oromucosal Spray as an Adjunctive Therapy in Advanced Cancer Patients with Chronic Uncontrolled Pain. J Pain Symptom Manage. 2018 Feb;55(2):179-188.e1. DOI: 10.1016/j.jpainsymman.2017.09.001. Epub 2017 Sep 18. PMID: 28923526.

10. Ruela LO, lunes DH, Nogueira DA, Stefanello J, Gradim CVC. Effectiveness of auricular acupuncture in the treatment of can-

\section{CONCLUSIONS}

Pain is a considerable concern of patients with advanced cancer and their caregivers, and its' management is challenging and often sub-optimal.

Even if pain relief can achieved adequately in a majority of cancer patients using the WHO guidelines, new pharmacological and non-pharmacological pain treatments should always be taken into consideration.

Compliance with ethics requirements: The authors declare no conflict of interest regarding this article. The authors declare that all the procedures and experiments of this study respect the ethical standards in the Helsinki Declaration of 1975, as revised in 2008(5), as well as the national law. Informed consent was obtained from all the patients included in the study.

cer pain: randomized clinical trial. Rev Esc Enferm USP. 2018 Dec 13;52:e03402. Portuguese, English, Spanish. doi: 10.1590/ S1980-220X2017040503402. PMID: 30570087.

11. Dhillon N, Kopetz S, Pei BL et al. Clinical findings of a palliative care consultation team at a comprehensive cancer center. $J$ Palliat Med 2008;11:191-197

12. Harsh V, Viswanathan A. Surgical/radiological interventions for cancer pain. Curr Pain Headache Rep 2013;17:331

13. Viswanathan A, Vedantam A, Hess KR, et al. Minimally Invasive Cordotomy for Refractory Cancer Pain: A Randomized ControIled Trial. Oncologist. 2019;24(7):e590-e596. doi:10.1634/theoncologist.2018-0570

14. Bang JY, Sutton B, Hawes RH, Varadarajulu S. EUS-guided celiac ganglion radiofrequency ablation versus celiac plexus neurolysis for palliation of pain in pancreatic cancer: a randomized controlled trial (with videos). Gastrointest Endosc. 2019 Jan;89(1):58-66.e3.

15. Ibrahim NM, Abdelhameed KM, Kamal SMM, Khedr EMH, Kotb HIM. Effect of Transcranial Direct Current Stimulation of the Motor Cortex on Visceral Pain in Patients with Hepatocellular Carcinoma. Pain Med. 2018 Mar 1;19(3):550-560.

16. Stearns LM, Abd-Elsayed A, et al. Intrathecal Drug Delivery Systems for Cancer Pain: An Analysis of a Prospective, Multicenter Product Surveillance Registry. Anesth Analg. 2020 Feb;130(2):289-297.

17. Fallon M, Giusti R, et al; ESMO Guidelines Committee. Management of cancer pain in adult patients: ESMO Clinical Practice Guidelines. Ann Oncol. 2018 Oct 1;29(Suppl 4):iv166-iv191. doi: 10.1093/annonc/mdy152. PMID: 30052758.

18. Lux EA, Schwittay A, Fentanyl buccal tablets in the treatment of breakthrough cancer pain. German cohort of a pan-European multicentre study]. MMW Fortschr Med. 2018 Jul;160(Suppl 4):18-23. German. doi: 10.1007/s15006-018-0728-1. Epub 2018 Jul 4. PMID: 29974433.

19. Vahedi HSM, Hajebi H, et al. Comparison between intravenous morphine versus fentanyl in acute pain relief in drug abusers with acute limb traumatic injury. World $\mathrm{J}$ Emerg Med. 2019;10(1):27-32.

20. Banala SR, Khattab OK, et al. Intranasal fentanyl spray versus intravenous opioids for the treatment of severe pain in patients 
with cancer in the emergency department setting: A randomized controlled trial. PLoS One. 2020 Jul 10;15(7):e0235461.

21. Mercadante S, Maseru F, Valenti M, Aielli F. Breakthrough pain in patients with head \& neck cancer. A secondary analysis of IOPS MS study. Oral Oncol. 2019 Aug;95:87-90.

22. https://www.nccn.org/professionals/physician_gls/pdf/pain. pdf, accessed on 27.10.2020

23. Matsuoka H, Iwase S., et al.Additive Duloxetine for Cancer-Related Neuropathic Pain Nonresponsive or Intolerant to OpioidPregabalin Therapy: A Randomized Controlled Trial (JORTCPAL08). J Pain Symptom Manage. 2019 Oct;58(4):645-653.

24. Kwekkeboom K, Zhang Y, Campbell T, Coe CL, Costanzo E, Serlin RC, Ward S. Randomized controlled trial of a brief cognitive-behavioral strategies intervention for the pain, fatigue, and sleep disturbance symptom cluster in advanced cancer. Psychooncology. 2018 Dec;27(12):2761-2769. doi: 10.1002/pon.4883. Epub 2018 Sep 27. PMID: 30189462; PMCID: PMC6279506.
25. Eyigor S, Uslu R, et al. Can yoga have any effect on shoulder and arm pain and quality of life in patients with breast cancer? A randomized, controlled, single-blind trial. Complement Ther Clin Pract. 2018 Aug:32:40-45

26. Cai $\mathrm{P}$, Li L, Hong $\mathrm{H}$, et al. A Chinese medicine warm compress (Wen Jing Zhi Tong Fang), combined with WHO 3-step analgesic ladder treatment for cancer pain relief: A comparative randomized trial. Medicine (Baltimore). 2018;97(11):e9965.

27. Kessel KA, Vogel MME, et al. Mobile Apps in Oncology: A Survey on Health Care Professionals' Attitude Toward Telemedicine, mHealth, and Oncological Apps. J Med Internet Res. 2016 Nov 24;18(11):e312

28. Yang J, Weng $L$, et al. Development and Testing of a Mobile App for Pain Management Among Cancer Patients Discharged From Hospital Treatment: Randomized Controlled Trial. JMIR Mhealth Uhealth. 2019 May 29;7(5):e12542. 
